\title{
Laparoscopic Versus Open Appendectomy, A Comparative Study
}

\author{
Muhammad Rauf Shaikh, Aun Ali, Summaya Saeed, Naveed Ali, \\ Hiba Rauf, Noshad A. Shaikh
}

\begin{abstract}
OBJECTIVE: To compare laparoscopic and open appendectomy in terms of complication rate. METHODOLOGY: This was a multicentric, retrospective study conducted at Dow University Karachi and Bantva Memon Hospital Karachi from January 2014 to December 2016. Patients with open and laparoscopic appendectomy were compared in terms of operative times, complication, hospital stay and conversion rate.

RESULTS: Total 90 patients were included in this study with 42 in laparoscopic group while 48 in open group. Laparoscopic appendectomy took longer to perform $(p=0.028) \&$ patients of open appendectomy showed longer hospital stay $(p=0.013)$ with comparable complication rate in both procedures.

CONCLUSION: Laparoscopic and open appendectomy both can be performed routinely for acute appendicitis without the additional risks of complications.
\end{abstract}

KEYWORDS: Appendectomy, open vs. laparoscopy, outcome

This article may be cited as: Shaikh MR, Ali A, Saeed S, Ali N, Rauf H, Shaikh NA. Laparoscopic Versus Open Appendectomy, A Comparative Study. J Liaquat Uni Med Health Sci. 2019;18 (02):90-3. doi: 10.22442/jlumhs.191820607

\section{INTRODUCTION}

Acute appendicitis is a common abdominal surgical emergency. In most of the surgical units conventional surgical approach for appendectomy is practiced ${ }^{1}$. Almost $6-7 \%$ of population may develop acute appendicitis during their lifetime. Appendectomy has been proven to the standard care for the treatment of acute appendicitis since its introduction in 1894 by McBurney ${ }^{2}$.

Literature already proves that laparoscopic surgery has many advantages like fast recovery, less pain at the site of surgery and shorter hospital stay ${ }^{3}$. In complicated appendicitis, laparoscopic appendectomy has major advantages like decreased risk of wound infection \& complete vision of peritoneal cavity ${ }^{4}$.

Whereas laparoscopic cholycystectomy is an established gold standard method of performing cholycystectomy and has replaced the open method long ago; laparoscopic appendectomy has yet to achieve this popularity ${ }^{5}$.

The purpose of present study is to compare the advantages and disadvantages of the two modes of surgery i.e. open and laparoscopic appendectomy for this most common type of abdominal emergency.

\section{METHODOLOGY}

This was a retrospective study carried out on a data of patients who were operated by open or laparoscopic approach for acute appendicitis from January 2014 to December 2016 in surgical unit 1, Dow University Karachi and Bantva Memon Hospital, Karachi. All patients of either sex with the diagnosis of acute appendicitis who underwent appendectomy during this period with either of the approach were included in the study. Open appendectomies performed via midline incision for associated peritonitis or diagnostic doubt were excluded from the study. Also excluded patients in whom preoperative diagnosis of any other pathology other than acute appendicitis was recognized. Severity of acute appendicitis was classified according to the disease severity score (Table I).

The cases were reviewed with regards to age, gender severity of acute appendicitis, operative time, complications \& hospital stay. Extension of surgical exposure was also compared (i.e. conversion to open for the laparoscopy group; while extension of incision for the open group). Open appendectomies were carried out via gridiron or Lanz incision. Laparoscopic appendectomy was carried out via three ports (one 10 $\mathrm{mm}$ port above the umbilicus, other one $5 \mathrm{~mm}$ port in the midline just above the pubis and third $10 \mathrm{~mm}$ port in the left iliac fossa. If required, fourth port was also introduced in right iliac fossa to ease the process of surgery. Remaining procedure remained same which includes performing appendicectomy after ligation or sealing of appendicular artery and retrieval of appendix via endo bag in laparoscopic approach.

\section{Statistical analysis}

All data was collected on preformed proforma for above mentioned variables \& compiled. Data was entered and analyzed in SPSS version 23. Mann Whitney $U$ test was used to compare means. A P - 
value of $<0.05$ was considered as significant.

TABLE I: ACUTE APPENDICITIS DISEASE SEVERITY SCORE

\begin{tabular}{|l|l|}
\hline Grade 1 & Inflamed. \\
\hline Grade 2 & Gangrenous. \\
\hline Grade 3 & Perforated with localized free fluid. \\
\hline Grade 4 & Perforated with regional abscess. \\
\hline Grade 5 & Perforated with diffuse peritonitis. \\
\hline
\end{tabular}

\section{RESULTS}

A total of 116 patients underwent appendectomy during the specified study period. However 26 didn't match the inclusion criteria and excluded from study. Hence data of 90 patients with acute appendicitis were finally included in the study. Among these 90 patients, laparoscopic appendectomy was performed in $42(47 \%)$ patients while open appendectomy in 48 $(53 \%)$ patients. The patient groups were compared in terms to age, gender and severity of appendicitis (Table II).

Operative time was $40 \pm 8$ minutes in laparoscopic group while it was $25 \pm 7$ minutes in open appendectomy (Table III). 8 (19.04\%) patients of laparoscopic group were converted to open technique while in $1(2.08 \%)$ patient of open appendicectomy procedure was converted to midline approach due to diffuse peritonitis. Mean hospital stay was $3 \pm 0.75$ days in open appendectomy group \& it was $1 \pm 0.50$ days in laparoscopic group. Wound infection was the most common complication noticed in $4(8.33 \%)$ patients of open surgery group. While 03(7.14\%) patients of laparoscopic surgery group developed postoperative complications. It includes port site infection in one patient and stump dehiscence in two patients.

TABLE II: GENERAL PATIENT CHARACTERISTICS

\begin{tabular}{|l|c|r|}
\hline & $\begin{array}{c}\text { Laparoscopic } \\
\text { appendectomy } \\
\text { group n = 42 }\end{array}$ & $\begin{array}{c}\text { Open appendectomy } \\
\text { group } \\
\text { n = 48 }\end{array}$ \\
\hline Age (in years) & $22 \pm 9$ years & $23 \pm 8$ years \\
\hline Sex & $28(66.6 \%)$ & $31(64.5 \%)$ \\
\hline Male & $14(33.3 \%)$ & $17(35.5 \%)$ \\
\hline Female & $5(11.9 \%)$ & $4(8.3 \%)$ \\
\hline Disease severity score & $8(16.6 \%)$ \\
\hline \multicolumn{2}{|c|}{$7(16.6 \%)$} & $24(50 \%)$ \\
\hline 2 & $20(47.6 \%)$ & $6(12.5 \%)$ \\
\hline 3 & $6(14.2 \%)$ & $6(12.5 \%)$ \\
\hline 4 & $4(9.5 \%)$ & \\
\hline 5 &
\end{tabular}

TABLE III:

COMPARISON BETWEEN LAPAROSCOPIC APPENDECTOMY AND OPEN APPENDECTOMY

\begin{tabular}{|l|r|r|r|}
\hline & $\begin{array}{c}\text { Laparoscopic } \\
\text { appendectomy } \\
\text { Group }(\mathrm{n}=42)\end{array}$ & $\begin{array}{c}\text { Open } \\
\text { appendectomy } \\
\text { Group }(\mathrm{n}=48)\end{array}$ & $\begin{array}{c}\mathrm{p}- \\
\text { value* }\end{array}$ \\
\hline $\begin{array}{l}\text { Operative time } \\
\text { (minutes) }\end{array}$ & $40 \pm 8$ & $25 \pm 7$ & 0.028 \\
\hline $\begin{array}{l}\text { Hospital stay } \\
\text { (days) }\end{array}$ & $1 \pm 0.5$ & $3 \pm 0.75$ & 0.013 \\
\hline Conversion & 8 & 1 & \\
\hline Complications & 3 & 4 & \\
\hline * $=$ Mann Whitney U test & & & \\
\hline
\end{tabular}

\section{DISCUSSION}

Acute appendicitis is one of the commonest abdominal surgical emergencies worldwide. It's most common differential diagnosis includes right ureteric colic, mesenteric lymphadenitis, meckel's diverticulitis, perforated peptic ulcer, ruptured ectopic pregnancy and torsion of right ovarian cyst etc ${ }^{6-10}$. Diagnosis of this disease is usually made clinically, however certain investigations like total leukocyte count with neoutrophilic shift \& ultrasound abdomen are commonly employed investigations to certify diagnosis. In case of doubt, CT scan Abdomen is advised. If not diagnosed at early stages, it may lead to severe peritonitis and sepsis ${ }^{11-12}$. Appendectomy is considered as simple and safe procedure. Despite this, it is associated with certain complications. Literature reports that laparoscopic appendectomy is associated with a higher complication rate and high cost as compared to the conventional open procedure $^{13}$. Although laparoscopic appendectomy has the advantages of optimal abdominal cavity exploration, less hospital stay and less post-operative pain which is in line with our study ${ }^{3}$.

The difference of the technique in both methods may transform the consequences in term of complication and $\operatorname{costs}^{14}$. Three ports laparoscopic approach for appendectomy can be adapted for all grades of severity of acute appendicitis including diffuse peritonitis ${ }^{15}$. Furthermore, use of handmade endo loop reduces the cost in comparison to the use of a linear stapler $^{16}$. Laparoscopic approach allows an optimal image of the operative field compared to open incision. Also possible complications of an abdominal incision, if large and contaminated, are significantly recognized in laparoscopic approach ${ }^{18}$. Our study also suggests low rate of wound related complications in laparoscopic approach as compared to 
open approach. Furthermore, no post-operative intra-abdominal collection or abscess formation was observed in our study in laparoscopic approach hence we cannot support the idea that laparoscopic surgery increases the risk of intra-abdominal abscess secondary to insufflation which is also noticed in study by Salmone G $2014^{17}$.

\section{CONCLUSION}

Laparoscopic appendectomy is an advanced \& feasible approach for the operative treatment of acute appendicitis. Present study elaborates that an experienced surgeon can effortlessly perform laparoscopic appendectomy. The complication rate and length of hospital stay was found to be less in laparoscopic appendectomy but operative time was slightly higher.

Recommendation: Laparoscopic appendectomy should be encouraged as it further allows us to explore the whole abdominal cavity and determine the associated pathology.

Ethical Permission: IRB permission letter No. IRB-136/BMH/Approval/2016/49 dated: 20-12-2016.

Conflict of Interest: The authors declare no conflict of interest.

Funding: This research did not receive any specific grant for the research work or to cover the cost to publish in open access from any funding agency.

\section{REFERENCES}

1. Costa Navarro $D$, Jiménez-Fuertes $M$, Illàn Riquelme A. Laparoscopic appendectomy: quality care and cost-effectiveness for today's economy. World J Emerg Surg. 2013; 8(1):45-49. doi: 10.1186/1749-7922-8-45.

2. Ali SM, Hassanain M. Laparoscopic versus open appendectomy. Saudi J Gastroenterol. 2011; 17 (4):225-6. doi: 10.4103/1319-3767.82571.

3. Sotelo-Anaya $E$, Sánchez-Muñoz $P$, Ploneda Valencia CF, de la Cerda Trujillo LF, Varela-Muñoz O, Gutiérrez-Chávez C, et al. Acute appendicitis in an overweight and obese Mexican population: A retrospective cohort study. Int J Surg. 2016; 32: 6-9. doi: 10.1016/ j.ijsu.2016.06.004.

4. Chung RS, Rowland DY, Li P, Diaz J. A meta-analysis of randomized controlled trials of laparoscopic versus conventional appendectomy. Am J Surg. 1999; 177(3): 250-6.

5. Kehagias I, Karamanakos SN, Panagiotopoulos S, Panagopoulos K, Kalfarentzos F. Laparoscopic versus open appendectomy: which way to go? World J Gastroenterol. 2008; 14(31): 4909-4914. doi: 10.3748/wjg.14.4909.

6. Mason RJ, Moazzez A, Moroney JR, Katkhouda N. Laparoscopic vs Open Appendectomy in Obese Patients: Outcomes Using the American College of Surgeons National Surgical Quality Improvement Program Database. J Am Coll Surg. 2012; 215(1): 88-89. doi: 10.1016/ j.jamcollsurg.2012.03.012.

7. Ingram AP, Cohen ME, Bilimoria KY, Pritts TA, Esposito TJ. Comparison of outcomes after laparoscopic versus open appendectomy for acute appendicitis at 222 ACS NSQIP hospitals. Surgery. 2010; 148(4): 625-35. doi: 10.1016/ j.surg.2010.07.025.

8. Pedersen AG, Petersen OB, Wara P, Ronning $\mathrm{H}$, Qvist N, Laurberg S. Randomized clinical trial of laparoscopic versus open appendicectomy. $\mathrm{Br} \mathrm{J}$ Surg. 2001; 88(2): 200-5.

9. Mascolino A, Scerrino G, Gullo R, Genova C, Melfa GI, Raspanti C, et al. Large retroperitoneal abscess extended to the inferior right limb secondary to a perforated ileal Crohn's disease: the importance of the multidisciplinary approach. G Chir. 2016; 37(1): 37-41. doi: 10.11138/gchir/2016.37.1.037

10. Paladino NC, Inviati A, Di Paola V, Busuito G, Amodio E, Bonventre S, et al. Predictive factors of mortality in patients with acute mesenteric ischemia: A retrospective study. Ann Ital Chir. 2014; 85(3):265-70.

11. Paterson HM, Qadan M, de Luca SM, Nixon SJ, Paterson Brown S. Changing Trends in Surgery for acute appendicitis, Br J Surg. 2008; 95(3): 363 $-8$.

12. Paik PS, Towson JA, Anthone GJ, Ortega AE, Simons AJ, Beart RW Jr. Intra abdominal abscess following laparoscopic appendicitis. J Gastroentest Surg. 1997; 1(2):188-92.

13. Tashiro J, Einstein SA, Perez EA, Bronson SN, Lasko DS, Sola JE. Hospital preference of laparoscopic versus open appendectomy: Effects on outcomes in simple and complicated appendicitis. J Pediatr Surg. 2016; 51(5): 804-9.

14. Vallina VL, Velasco JM, McCulloch CS. Laparoscopic versus conventional appendectomy. Ann Surg. 1993; 218(5): 685-692.

15. Tarnoff M, Atabek U, Goodman M, Alexander JB, Chrzanowski F, Mortman K, et al. A comparison of laparoscopic and open appendectomy. JSLS. 1998; 2(2): 153-8.

16. Gotz F, Pier A, Bacher C. Modified laparoscopic 
appendectomy in surgery: a report on 388 operations. Surg Endosc. 1990; 4(1): 6-9.

17. Salamone G, Licari L, Atzeni J, Tutino R, Gulotta G. Histologic considerations about a rare case of recurrent incisional hernia on McBurney incision. Ann Ital Chir. 2014; 85(ePub). pii: S2239253X14022828.

18. Yu G, Han A, Wang W. Comparison of laparoscopic appendectomy with open appendectomy in treating children with appendicitis. Pak J Med Sci. 2016; 32(2):299-304. doi: $10.12669 /$ pjms.322.9082.

AUTHOR AFFILIATION:

Dr. Muhammad Rauf Shaikh

Assistant Professor of Surgery

Dow Medical College, DUHS/ Civil Hospital

Karachi, Sindh-Pakistan.

\section{Dr. Aun Ali}

Associate Professor of Surgery

United Medical \& Dental College

Karachi, Sindh-Pakistan.

Dr. Summaya Saeed (Corresponding Author) Assistant Professor of Surgery

Dow Medical College, DUHS/ Civil Hospital

Karachi, Sindh-Pakistan.

Email: summayasaeed@hotmail.com

\section{Dr. Naveed Ali}

Associate Professor of Surgery

Dow International Medical College, DUHS

Karachi, Sindh-Pakistan.

\section{Dr. Hiba Rauf}

House Officer Surgery

Dow Medical College, DUHS/ Civil Hospital

Karachi, Sindh-Pakistan.

\section{Dr. Noshad A. Shaikh}

Professor of Surgery

Dow Medical College, DUHS/ Civil Hospital

Karachi, Sindh-Pakistan. 